\title{
A Resistência Escrava no Rio Grande do Sul: Reação ou Afirmação?
}

\author{
Helga I.L. Piccolo*
}

O sistema escravista no Rio Grande do Sul - ressalvadas especificidades de sua formação social - apresentou todas as formas de resistência que a produção do conhecimento histórico mais recente sobre o Brasil vem registrando e analisando. A pesquisa no Rio Grande do Sul sobre o escravismo africano vem confirmando que, também aqui, ocorreram o que para Eduardo Silva (1989:62) são "formas explícitas de resistência física (fugas, quilombos e revoltas)" [...] a "a resistência do dia a dia - roubos, sarcasmos, sabotagens, assassinatos, suicídios, abortos", bem como "aspectos menos visíveis, porém profundos, de uma ampla resistência sócio-cultural".

Pela condição de província fronteiriça, as chamadas "fugas para fora” (SILVA, 1989:71) têm dimensões específicas. Não é apenas a fuga para o interior, para a mata, formando ou não quilombos, que a documentação revela.

Associar fugitivo com quilombola é muito comum no "discurso" da autoridade constituída e/ou da classe dominante. Lê-se, por exemplo, no jornal Correio do Sul, Ano I, de 5a-feira, 25 de novembro de 1852, p.2, que em Rio Grande, dois escravos já velhos, de D. Luíza Gomes de Oliveira,

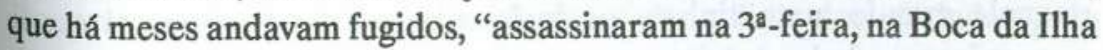
do Machadinho, a um escravo do Sr. Leonídio Antero da Silveira". Os assassinos que se apresentaram na cadeia da cidade confessando o crime "com o mais assombroso sangue-frio", justificaram seu ato por descon-

* Professora na Universidade Federal do Rio Grande do Sul. 
fiarem que a vítima avisaria a seu senhor quando "os dois quilombolas entravam na ilha".

$\mathrm{O}$ assassinato, como tentativa de resistência à captura, também está implícito no aviso, do Ministro da Justiça, ao Presidente da Província, com data de 4 de março de 1835 (AHRGS, cód. B-1.106), de "que foi confirmada a pena de morte dadas a Manoel Crioulo, escravo de Manoel Veríssimo Esteves da Fonseca, por ter assassinado a Manoel Elias de Moraes, seu antigo senhor moço que foi morto quando buscava o réu para prendê-lo já que se encontrava aquilombado com outros".

O quilombo como "espaço" que os escravos procuravam conquistar e preservar, levou a inevitáveis enfrentamentos. Em 23 de julho de 1854, pela Repartição de Polícia foi ordenado ao Capitão do Corpo Policial de Porto Alegre que seguisse, com uma escolta de 12 praças, à Estância de Gravataí, para prender escravos ali aquilombados. Apesar da forte resistência, "a ponto de ferirem gravemente a um dos soldados da escolta", foram capturados três e mortos dois escravos e apreendidos dois desertores da Cia de Inválidos (sic) e sete paisanos que "se comunicavam com os referidos quilombolas" (AN IJ ${ }^{1} 57$ ). Portanto, 0 quilombo se "comunicava" com o mundo a ele exterior e era refúgio para não escravos.

Nem sempre o confronto entre o sistema sócio-econômico oficial e os escravos resultava em mortes e/ou ferimentos. No sábado, 8 de novembro de 1879 , o jornal $O$ Mercantil noticiava à página três: "Hoje foi surpreendida a nossa população com um fato estranho (pelo menos em nossos dias), fato cuja responsabilidade cabe diretamente à nossa edilidade. Uns quantos quilombolas atravessaram as ruas da cidade $e$ foram apreendidos no cerrado do Capão que demora na Rua Direita, da quadra entre as Ruas da Igreja e Arvoredo. Sim senhores, é verdade, ali naquele grande mato tinham os fugidos o seu quartel-general sendo apenas incomodados à noite em razão dos tigre que os assaltavam! Quem diria que no coração de nossa Porto Alegre, se formaria um covil de quilombolas!" O processo de urbanização que, por si só, facilitava aos escravos "esconderem-se", também afrouxava vínculos e relações com as quais o sistema contava para exercer o controle social sobre os dominados, escravos ou não.

Outro exemplo de "fuga para dentro", isto é, "para o interior da própria sociedade escravista" (SILVA, 1989:72) nos é dado pela $A$ 
Federação, no dia 12 de janeiro de 1885 à página três: "Somos informados de que nas proximidades do Cerrito existe um novo quilombo, que conta regular número de pretos fugidos. Na semana passada alguns desses pretos carnearam rezes na chácara do Sr. Henrique de Moraes Patacão e assaltaram a dispensa da quinta do Sr. José de Campos de onde furtaram grande quantidade de mantimentos. Os moradores daquelas imediações reclamam a atenção da polícia, pois ali vivem em completo sobressalto". Sem maiores comentários, o jornal do Partido Republicano Riograndense transcrevia a notícia procedente de Pelotas, tradicional centro escravista do Rio Grande do Sul.

A formação de um quilombo como possibilidade para a obtenção da liberdade foi pensada pelo escravo. Mas nem sempre houve receptividade a esta possibilidade. A preta Maria, escrava de Pedro Andára, informa a seu senhor que em 21 de outubro de 1849, foi convidada pelo preto Antonio, escravo do Comendador Boaventura Rodrigues Barcellos, para fugirem para um quilombo que se estava formando, onde ela seria forra. Delatado, a defesa de Antonio foi a negativa do convite (APERGS, Justiça - Doc. 248, maço 6, Pelotas).

A fuga também se fazia para o Estado Oriental, onde a escravatura fora abolida em 1842. Era uma decisão tomada por iniciativa dos próprios escravos ou resultado de um aliciamento feito por "caudilhos" platinos que prometiam a alforria em troca de serviços prestados nas suas hostes. Assim, em 29 de novembro de 1864, o Presidente da Província oficia ao Ministro da Justiça (AN IJ ${ }^{1} 586$ ) sobre "notícias de uma insurreição de escravos na Vila do Taquary cujo plano, dizia-se, eram saquear a povoação, roubarem as mulheres e com elas fugirem para o Estado Oriental". Segundo o Juiz de Direito que coligiu as informações a respeito, transmitindo-as ao Presidente da Província, "os escravos Boaventura, Domingos, Carlos, Bento, João e Joaquim, aliciados pelo liberto João Marçal, convidaram diversos parceiros para em um dia que deviam designar, reunirem-se junto ao cemitério e dali marcharem sobre a Vila e munidos de armas e dinheiro retirarem-se para o Estado Oriental". Este projeto, ouvido por uma escrava de Francisco Caminha, foi revelado à autoridade que tomou as providências cabíveis. A notícia que corria era de ter chegado "a este Termo vindo do Estado Oriental onde estava refugiado, um preto irmão de dois dos escravos implicados". O escravo Joaquim, interrogado, declara, numa "coarctada malévola sugerida pela astúcia", que os autores do plano eram o Coletor das 
Rendas Gerais e Provinciais Bernardo dos Santos Praia e Bernardino José Correa. Portanto, delação e dissimulação (ou astúcia) faziam parte das estratégias dos que eram contra o plano e dos que estavam de acordo com ele.

A "fuga para fora" esteve muitas vezes associada à idéia do levante. E na conjuntura de mais uma intervenção armada brasileira no Prata (contra Aguirre e Lopez), numerosos planos e (ou tentativas de) levantes/revoltas/insurreiçôes são registrados pela documentação oficial (Correspondência dos Presidentes da Província aos Ministros da Justiça - AN IJ $^{1} 587$ e IJ $^{1}$ 856; MAESTRI FILHO, 1984:148-54; PINTO, 1982:36-44).

Levantes, cujo objetivo era a obtenção da liberdade dentro do sistema escravista vigente, também foram "descobertos". Na correspondência de 29 de agosto de 1863 , do Presidente da Província, ao Ministro da Justiça (AN IJ ${ }^{1}$ 585), encontram-se informações sobre uma tentativa insurrecional na freguezia de Nossa Senhora dos Anjos da Aldeia. O Chefe de Polícia, encarregado da repressão, diz no seu ofício ao Presidente da Província que "dos interrogatórios veio ao conhecimento que os escravos da fazenda de Francisco Maciel desde maio começaram a aliciar outros para levantarem-se contra seus senhores, tomarem-lhes as armas e o dinheiro e reclamarem depois sua liberdade exigindo-a pela força se the a não dessem". Esses escravos encontraram cúmplices nas fazendas vizinhas e mandaram emissários para o Pinhal, Passo Grande e Sapucaia, designando o dia 26 do corrente para se reunirem no Passo do Butiá, alistaram-se, acamparem no campo do Chará, para no domingo dia 30 atacarem o povoação da Aldeia, seguindo depois para o Passo Grande onde reunidos todos, deviam marchar para a capital. Segundo a autoridade, este plano foi confirmado por um dos chefes, escravo do dito Maciel. Os outros escravos evadiram-se. Para 0 sistema, o que interessava é que o "tenebroso projeto" foi abortado.

O mesmo objetivo - obterem os escravos a sua liberdade - é o de uma insurreição que deveria ter lugar em Porto Alegre, na noite de 24 de junho de 1868. O plano foi denunciado pelo escravo Antônio Maria que o levou ao conhecimento de seu senhor. Conforme ofício do Chefe de Polícia, datado de 27 de junho, o escravo denunciante informou que foi convidado, por um pardo de nome Dionísio, escravo do negociante Francisco Ferreira Porto, que lhe disse que havia muita gente pronta para 
a insurreição. Mandado vir à presença do Delegado de Polícia da Capital, o escravo Dionísio confessou o plano denunciando, como seus cabeças, os escravos Theodoro e Patrício daquele negociante. O plano deveria ser executado na noite do Espírito Santo mas Patrício considerando que ocorreriam muitas desgraças desnecessárias, porque haveria confusão quando os insurgentes tomassem a Praça do Palácio, que deveria estar cheia de povo a assistir às festas, e que esta confusão poderia fazer malograr o plano, ficou resolvido a transferência para a noite de São João. Como não havia armamento, Patrício encomendara a um escravo do Capitão Manoel Joaquim, morador no Caminho do Meio, doze dúzias de cabos de lança para neles encravarem-se facas e quaisquer outros instrumentos de forma a servirem de lanças. Deveriam sair a uma hora da noite da chácara do Capitão Manoel Joaquim, formando os insurgentes quatro divisões: uma se dirigiria ao Quartel-General da Guarda Nacional, outra ao Laboratório Pirotécnico, uma terceira ao Arsenal de Guerra (todas elas para se proverem de armas). A $4^{\mathrm{a}}$ divisão iria à Cadeia soltar os presos que, sendo libertados, "por certo auxiliariam a insurreição". Ainda, segundo Patrício, contavam os insurgentes com o auxilio de prisioneiros paraguaios. O entendimento foi feito com Gabino Flores que, interrogado, afirma se lembrar que o escravo lhe falara sobre o assunto, mas não dera importância, porque achou que estava ébrio (AN IJ $^{1}$ 591).

Portanto, se verdadeiras as informações, uma ampla rede de relações havia sido estabelecida. Foi o exemplo de uma revolta pensada que, como a maioria, não passou de uma tentativa cujo êxito esbarrava na falta de unidade entre os escravos.

Mas há a acrescentar que o Presidente da Província e o Chefe de Polícia propõem a liberdade ao escravo denunciante, "liberdade que servirá para tornar vigilantes outros escravos que de certo procurarão denunciar ao governo iguais atentados". Portanto, conforme Eduardo Silva (ob. citada, p.70), revoltas "foram o pesadelo do tempo".

Não apenas a possibilidade de uma revolta - portanto uma ação coletiva da parte dos escravos - mas também uma ação individual, fazia com que as autoridades e os senhores tivessem o máximo cuidado para evitar que os cativos andassem armados.

Jacinto, escravo do Marechal Francisco das Chagas Pinto, revistado em 18 de agosto de 1835 (lembrando que era véspera da eclosão da 
Guerra dos Farrapos) numa venda no centro de Porto Alegre, encontrouse em seu poder um "estoque". Fugiu ao ser preso. (APERGS, Justiça, Doc. 757, maço 26, 1847 - Porto Alegre.)

O escravo Manoel, que andava fugido há nove dias, assassina, em 20 de maio de 1850 , o preto forro José Venâncio que tentava pegá-lo, no largo de Santa Cruz da cidade de Pelotas. O réu andava armado com uma pistola, um punhal, um ferro de pedreiro, alguma pólvora e bala, armamento que, segundo o interrogatório a que foi submetido no processo-crime, havia ganho no jogo. (APERGS, Justiça, Doc. 303, maço 7,1850 - Pelotas.)

Ações coletivas houve que foram consideradas como insurreição ou sublevação para justificar a repressão.

Em 11 de abril de 1873 (AN, IJ $^{1}$ 597), na cidade de Pelotas, alguns pretos escravos de João Mendes de Arruda e outros livres em número de dez, promoveram uma insurreição, ofendendo a tranqüilidade pública, ferindo gravemente três praças da Polícia. Os autores desta insurreição entraram na cidade, na noite do citado dia, "dando vivas à liberdade e à república". Tropa e povo seguiram em perseguição dos desordeiros que "se reuniram em uma casa onde tinham preparado um baile, mas sendo avisados por um espia, fugiram todos para a casa do referido Arruda conseguindo apenas prender uma preta escrava do mesmo Arruda que confessou quem eram os autores e quais os seus planos". Não houve delação, mas solidariedade.

Na campanha abolicionista no Rio Grande do Sul, o ano de 1884 é o da grande emancipação de escravos com a cláusula de prestação de serviços, a que muitos "libertos contratados" se negavam (Relatório do Presidente da Província José Julio de Albuquerque Barros, de 19 de outubro de 1885).

Notícias veiculadas pelo Jornal do Comércio dão conta de que "0 Delegado de Polícia do Termo de Pelotas recebeu comunicado de que os escravos e libertos da fazenda São João pertencente aos herdeiros do finado Comendador Manoel Vieira Braga, situado além do Arroio Grande, em Pelotas, a 12 léguas da cidade, depois de tentarem contra a existência do respectivo capataz que a custo conseguira fugir com vida, se haviam colocado em atitude de resistir a toda e qualquer intimidação que tivesse por fim contê-los no trabalho e na obediência. Esses escravos e libertos constituem um número de 17 pessoas constando que a eles se 
acham reunidos muitos outros de igual condição e com as mesmas disposições. O Delegado de Polícia com praças de que pode dispor, segue para o lugar da sublevação, para manter a ordem e o respeito à lei" (jornal citado, Porto Alegre, dia 12 de março de 1885). A escolta "chegou sábado último à estância, já de noite e sem mais preâmbulos dirigiu-se a seus proprietários para que lhe apontassem os amotinados". Conhecidos estes, foram presos e guardados convenientemente, ameaçando aos demais de igual processo se tentassem sair fora dos limites dos seus contratos. Dos presos, em número de seis, três são escravos e três libertos com condição de serviços. No ato da prisão, os dois opuseram alguma resistência, fugindo depois para o mato sendo perseguidos e submetidos. (Jornal citado, $3^{\mathrm{a}}$-feira, dia 17 de março.)

Agressões (com ferimentos e/ou mortes) praticadas por escravos foram reações contra as mais variadas situações por eles vividas.

O escravo Francisco feriu em 14 de dezembro de 1851, na freguezia de Sant'Anna, a seu senhor Ignácio Vieira de Souza, devido ao castigo recebido (APERGS, Justiça, Doc. 19, maço 01, São Leopoldo - 1852). Do processo, desiste o senhor, alegando que se feriu sozinho. O delegado de Polícia discorda da conclusão do processo porque os motivos "podem não ser a inocência do seu escravo e sim o temor a perdê-lo".

$\mathrm{O}$ escravo alfaiate Antônio, insulta, surra e fere, em 28 de fevereiro de 1844, a Augusto Bernardino da Silva, que "estava com outros se divertindo na casa do preto forro Adão na festa que com consentimento do Chefe de Polícia fazia a Irmandade da Senhora do Rosário". As palavras insultuosas proferidas pelo escravo contra o forro, conforme a única testemunha, foram: cabrão, filho da puta e bode. (APERGS, Justiça, Doc. 721, maço 25, 1845 - Porto Alegre.)

O escravo João Antonio, de propriedade de Leandro Pires Cerveira, natural de Moçambique, 70 anos, solteiro, lavrador, morador no Distrito de Sant'Anna, agrediu com uma faca e matou ao índio José Ribeiro, no dia 16 de agosto de 1863 . O fato aconteceu numa venda onde o escravo entrou e encontrou o índio que o tratou de "negro cativo" (APERGS, Justiça, Doc. 53, maço 2, 1863 - São Leopoldo).

João, escravo de Henrique Panitz, matou em 11 de junho de 1846, o cabra Thomaz, do mesmo senhor. Segundo o inquérito, João teria desobedecido a seu senhor e, por isto, saíra de casa perseguido por Thomaz para que retornasse e recebesse o castigo. Agredido, João reagiu 
e matou seu parceiro com facadas. A todas as pessoas que tentam prendê-lo, ele agride. Segundo o processo, a sua resistência estava relacionada com o fato de residir no lugar apenas há 3 meses, não conhecendo a língua "local" (o escravo era nagô). Não entendendo a ordem recebida, não a cumpriu. Daí o castigo e sua reação (APERGS, Justiça, Doc. 03, maço 01, 1846 - São Leopoldo).

José Luís, nação cabinda, escravo do Comendador Cipriano Rodrigues Barcelos, assassinou em 9 de abril de 1848 o capataz Francisco de Oliveira. Apesar de perseguido, conseguiu evadir-se, não sendo preso. Também não foi julgado por estar em lugar incerto. Dos depoimentos de dois escravos informantes, sabe-se que o capataz mandou o escravo José Luis ajudar a arrumar uma mesa que virara, dizendo-lhe "pai ajuda ali". O preto respondeu que tinha nome e que não se chamava pai. Perguntado pelo capataz como se chamava, respondeu-lhe que já podia saber seu nome porque já estava aí há dias. Reagindo a esta resposta do escravo, que, assim, afirmava a sua condição de homem que tinha nome, o capataz deu-lhe com o cabo do relho e o agarrou para amarrá-lo, quando levou a facada (APERGS, Justiça, Doc. 213, maço 5, 1848 - Pelotas).

O escravo Francisco Xavier, natural de Angola, matou em setembro de 1851, na Serra dos Tapes, o escravo José (ambos pertenciam ao mesmo proprietário, Hermenegildo José da Costa). Fugiu e passadas algumas horas apresentou-se ao seu senhor. Inquirido, contestou ser o matador e que, se fugira, fora por medo de ser castigado por seu senhor e incriminado pelo crime cometido, segundo ele, por "dois quilombolas que saíram do mato" (APERGS, Justiça, Doc. 373, maço 8, 1852 Pelotas). Possivelmente o negro sabia que a Serra dos Tapes era refúgio de escravos fugitivos que ali formaram diversos quilombos e acusar quilombolas era uma estratégia de sobrevivência.

Eva, escrava de D. Perpétua Merenciana de Jesus, matou com "pau de moinho e machado" em 5 de fevereiro de 1850 , no $3^{\circ}$ Distrito de Porto Alegre, a três filhos menores de sua senhora moça: Maria, de 12 anos, Manoel de 5 anos e Cândida, de 4 anos. A ré confessa que, estando só em casa com as crianças e tendo vontade de comer pão e melado que tinha dentro de uma caixa fechada, arrombou a dita caixa e tirou o pão e o mel. A morte das crianças se devia ao fato da menina mais velha dizer que "havia de contar à sua mãe que ela tinha arrombado a caixa". No $1^{\ell}$ interrogatório, a ré diz que não tinha pesar de ter morto as crianças 
porque todas eram muito más para ela, que lhe davam pinicões e além disso faziam queixa dela e por isto recebia muita pancada de sua senhora moça. No julgamento, a ré nega a autoria do crime e perguntada por que antes o confessara, respondeu que fizera essa declaração insinuada por sua senhora moça (APERGS, Justiça, Doc. 824, 1850 - Porto Alegre).

Em 26 de dezembro de 1866, no $1^{1}$ distrito de Rio Grande, Clara escrava do Capitão de Mar e Guerra Reformado Manoel Joaquim dos Campos, assassinou sua filha, de 18 meses, com um golpe no pescoço, atirando-a depois dentro do poço. Em seu interrogatório, declara que cometera o crime devido a "raiva com que estava" (AHRGS, Grupo Documental: Polícia, maço 18).

O homicídio relacionado com a "família escrava" e com a disputa pela "amizade" de uma escrava também deve ser considerado como uma forma de resistência e de afirmação da condição humana do cativo.

Em 1845, na Estância de São Miguel, situada em Barba Negra, distrito de Triunfo, Manoel Maria, de nação moçambique, matou seu parceiro José (ambos eram escravos de D. Leonarda Leite de Oliveira Salgado). Os dois disputavam a mesma preta e pelos "favores dela brigaram e, conforme o réu, fora obrigado a matar para se defender" (APERGS, Justiça, Doc. 722, maço 25, 1845 - Porto Alegre).

Em 11 de fevereiro de 1847, o escravo Matheus, natural de Moçambique, esfaqueou sua amásia, a preta escrava Felisbina, por ter ela estado com outro negro. Das facadas, a escrava morreu, em 17 de fevereiro (APERGS, Justiça, Doc. 189, maço 4, 1847 - Pelotas).

João Fidelis, escravo do Tenente Coronel Patricio Vieira Rodrigues, assassinou, em 15 de novembro de 1852, no Distrito de Dores do Camaquã, o escravo Manoel, do mesmo senhor. João Fidelis era casado legitimamente, há muitos anos, com uma parda livre Maria Felicidade (o réu frisa no interrogatório que foi casado por um padre de nome Francisco). Matou - sem ser esta a sua intenção - seu parceiro, ao ser por este acometido depois de encontrá-lo "deitado com sua mulher" na roça (APERGS, Justiça, Doc. 854, maço 29, 1853 - Porto Alegre).

Se o escravo foi assassino, também foi suicida.

Em 10 de janeiro de 1855, a escrava Mércia, suicidou-se, afogandose no rio Caí, levando consigo um filho de 10 para 11 meses. Segundo o Subdelegado da Freguezia de Sant'Anna, "o motivo que se julga a levou a tal desespero foi por ter vindo para fora da cidade onde ela esteve mais 
de 10 anos [...]" (AHRGS, Grupo Documental: Polícia, maço 10). Deslocada, não se adaptou ao novo meio.

Em 2 de dezembro de 1867, no $1^{\circ}$ Distrito do rumo de Sant'Anna do Livramento, o escravo Filippe suicidou-se, degolando-se, ao ser agarrado pelo soldado que o perseguia por estar fugido ( $\mathrm{AN}, \mathrm{IJ}^{1} 590$ ).

Por sofrer de desarranjo mental e se dar a quase constante embriaguez, suicidou-se (conforme averiguaçōes do Subdelegado de Polícia do $1^{\circ}$ Distrito de Pelotas - ofício de 28 de fevereiro de 1870, AHRGS, Grupo Documental: Polícia, maço 4) o escravo Luís.

Em 2 de maio de 1882, foi feito o auto de Corpo de Delito no cadáver do preto Adolpho. Por levantamentos feitos e referências de pessoas que conheciam o preto, segundo a Delegacia de Polícia de Porto Alegre, Adolpho "ultimamente se achava sofrendo de hipermania suicida, em conseqüência do vício de masturbação a que se tinha dado" (AHRGS, Grupo Documental: Polícia, maço 12). Perguntamos, necessidades biológicas não atendidas? Carências afetivas.

Necessidades biológicas e/ou carências afetivas, possivelmente estiveram na raiz de casos de estupro registrados.

Em 10 de abril de 1866, às margens do rio que banha São Leopoldo, Bento, escravo de D. Anna Altanásia, fez proposta obcenas a Anna Maria Kiling e, frente a resistência da mesma, a espancou o mesmo acontecendo com sua filha (APERGS, Justiça, Doc. 87, maço 04, 1867 - São Leopoldo).

Em 23 de janeiro de 1869, no Termo de Taquara, o escravo Bonifácio, de Barros \& Irmãos, estuprou D. Thereza Pinheira, mulher branca de mais de 50 anos (AN, $\mathrm{IJ}^{1} 592$ - 1869).

A "leitura" desses atentados também pode ser no sentido de uma afirmação do negro perante a raça branca.

$\mathrm{Na}$ defesa de "sua verdade", o escravo Guilherme contestou o seu senhor, "o comerciante abastado e de conceito" José Fernando Granja. Segundo notícia veiculado pelo Jornal do Comércio, de 16 de setembro de 1875 , "na cadeia civil estava sendo imoderadamente castigado o escravo por não haver querido entregar a seu senhor uma Caderneta da Caixa Econômica onde, para sua liberdade depositara a quantia de $220 \$ 000$ " (AN, $\mathrm{IJ}^{1}$ 605). No ofício do Presidente da Província, está anexo um requerimento do escravo, onde alega que tendo que entregar ao sell senhor a quantia de $100 \$ 000$, como $1^{\mathrm{a}}$ prestação para sua alforria, nẩo 
quis este recebê-la, exigindo para este fim 1:500\$000, quantia pela qual tencionava vendê-lo para fora da província. Ainda, segundo o escravo, o seu senhor impôs que lhe entregasse a caderneta, sem o que continuaria a mandá-lo castigar. Esta versão não coincide com a do senhor que, segundo o Chefe de Polícia, "mandara recolher o escravo à cadeia correcionalmente".

\section{Conclusão}

A documentação consultada ao desvelar aspecto do escravismo no Rio Grande do Sul mostra que o escravo não foi submisso nem acomodado e que, dentro dos limites impostos pelo sistema escravista, reagiu afirmando-se como ser humano que era e rejeitando na "sua prática" a coisificação.

\section{Bibliografia}

SILVA, Eduardo. Fugas, Revoltas e Quilombos. In Negociação e Conflito. São Paulo, Companhia das Letras, 1989.

\section{Fontes}

Correspondência dos Presidentes da Província de São Pedro do Rio Grande do Sul aos Ministros đa Justiça. Série $\mathrm{IJ}^{1}$ - Arquivo Nacional (AN).

Grupo Documental - Polícia. Arquivo Histórico do Estado do Rio Grande do Sul (AHRGS).

Processos-Crime. Arquivo Público do Estado do Rio Grande do Sul (APERGS). 